\section{OP0060 MICE DEFICIENT IN LEPTIN (OB/OB) OR IN LEPTIN RECEPTOR (DB/DB) HAVE A MILDER FORM OF ANTIGEN-INDUCED ARTHRITIS}

${ }^{1} \mathrm{~N}$ Busso, ${ }^{1} \mathrm{~A}$ So, ${ }^{1} \mathrm{~V}$ Péclat, ${ }^{2} \mathrm{C}$ Gabay. ' Service de Rhumatologie, CHUV, Lausanne; ${ }^{2}$ Division de Rhumatologie, HUG, Geneva, Switzerland

\subsection{6/annrheumdis-2001.821}

Background Leptin, the product of the ob gene, is synthesised exclusively by adipocytes to regulate the body weight in a central manner through its interaction with the long isoform of leptin receptor, Ob-Rb. However, Ob-Rb is also expressed in lymphoid tissues and leptin has been shown to regulate the cell-mediated immunity.

Objectives To examine the role of leptin in vivo by analysing the phenotype of mice deficient in leptin $(\mathrm{ob} / \mathrm{ob})$ or in Ob-Rb $(\mathrm{db} /$ $\mathrm{db})$ during antigen-induced arthritis (AIA).

Methods Arthritis was induced by an intraarticular injection of methylated bovine serum albumin (mBSA) in the knees of previously immunised ob/ob, db/db, control littermates and wild-type mice, all in C57BL/6 background. The severity of arthritis was determined by $99 \mathrm{~m}$ Technetium $(99 \mathrm{~m} \mathrm{Tc})$ uptake. In addition, the degree of articular inflammation was also determined after sacrifice by histology scoring. Levels of circulating immunoglobulins and antibodies against mBSA were measured by ELISA. The responses of isolated lymph node cells to mBSA were also examined.

Results Joint inflammation, as measured by $99 \mathrm{~m}$ Tc uptake, was significantly reduced in ob/ob mice as compared with control littermates and wild-type mice (on day 1 of arthritis: $p<0.002$ and $\mathrm{p}<0.001$, respectively; on day $3: \mathrm{p}<0.03$ and $\mathrm{p}<0.02$, respectively). In addition, histology studies showed that ob/ob mice had markedly less synovial inflammation than lean controls $(\mathrm{p}<0.04)$. In contrast, there was no difference in proteoglycan content within the articular cartilage as assessed by Safranin-O staining. The in vivo production of antibodies against $\mathrm{mBSA}$ was significantly decreased in ob/ob mice as compared with controls $(\mathrm{p}<0.03)$. Circulating levels of total and anti-mBSA IgG1, IgG2a, and IgG2b were significantly lower in ob/ob mice than in controls, whereas levels of $\operatorname{IgM}$ were not different. In vitro lymph node cell proliferation in response to mBSA was significantly reduced in ob/ob mice as compared with controls. In addition, production of interferon-gamma by cultured lymph node cells was significantly lower in ob/ob than in control mice, whereas opposite results were observed for IL-10. Experiments performed in $\mathrm{db} / \mathrm{db}$ mice confirmed the findings in leptin-deficient mice.

Conclusion Leptin appears to regulate both the cellular and humoral components of the immune response against mBSA and to contribute to the mechanisms of joint inflammation in AIA. In addition, these results demonstrate that the effects of leptin on the immune system are mediated through its interaction with $\mathrm{Ob}-\mathrm{Rb}$.

\section{THU0025 SERUM LEVELS OF STROMELYSIN-1 (MMP-3), GELATINASE B (MMP-9), TIMP-1 AND TIMP-2 IN HISTOLOGICAL VARIANTS OF RHEUMATOID SYNOVITIS}

${ }^{1}$ PA Klimiuk, ${ }^{1} S$ Sierakowski, ${ }^{2} \mathrm{R}$ Latosiewicz, ${ }^{3} \mathrm{~B}$ Cylwik, ${ }^{2} \mathrm{~J}$ Skowronski, ${ }^{1} \mathrm{~J}$ Chwiecko. ${ }^{1}$ Department of Rheumatology and Internal Diseases; ${ }^{2}$ Department of Orthopedic Surgery; ${ }^{3}$ Department of Pathological Anatomy, Medical University of Bialystok, Bialystok, Poland
Background Rheumatoid synovitis is a chronic progressive disease with an invasive and tissue destructive infiltrate of lymphocytes, macrophages and synoviocytes. Matrix metalloproteinases (MMPs) and tissue inhibitors of metalloproteinases (TIMPs) produced by these cells play an important role in the remodelling of the articular tissue in rheumatoid arthritis (RA).

Objectives In the study we investigated whether the histological appearance of the disease could be predicted from the serum concentration of MMPs and their inhibitors.

Methods The study included tissue and serum samples taken from 37 patients with clinically active RA and 30 with osteoarthritis (OA). Two types of RA were distinguished after morphological analysis of synovial specimens. Twenty two samples presented only diffuse infiltrates of mononuclear cells without any further microanatomical organisation, whereas lymphocytic conglomerates with germinal centre-like structures were found in 15 specimens. Serum concentrations of stromelysin-1 (MMP3), gelatinase B (MMP-9), TIMP-1 and TIMP-2 were assessed by means of ELISA method.

Results The unique serum profiles of MMPs and TIMPs were determined in both histological types of RA synovitis. In comparison with $\mathrm{OA}$ patients constituting a control group, there were detected higher serum concentrations of MMP-3 and MMP-9 in RA patients (in both cases $\mathrm{p}<0.001$ ). Elevated concentrations of MMPs were found in the serum of RA patients with follicular synovitis than in those with diffuse $(\mathrm{p}<0.01$ and $\mathrm{p}<0.001$ respectively). Serum of RA patients presented also elevated levels of TIMP-1 and TIMP-2 in comparison with OA patients $(\mathrm{p}<$ 0.001 and $\mathrm{p}<0.01$ respectively). TIMP-1 dominated in the serum of RA patients with follicular synovitis comparing with those with diffuse $(\mathrm{p}<0.05)$. The serum concentrations of MMPs and TIMP-1 could clearly identify patients with two different histological types of rheumatoid synovitis and with OA. The clinical data analysed in our study implicated that rheumatoid disease in patients with follicular synovitis was more severe than in those with diffuse infiltrates.

Conclusion The distinct histological appearance of rheumatoid synovitis correlated with serum profile of MMPs or TIMP-1 reflects varied clinical activity of the disease and confirms its heterogeneity. These associations also suggest that patients with different morphological forms of RA might require different treatment regimens.

\section{THU0026 A SINGLE NUCLEOTIDE POLYMORPHISM ON THE IL-10 LOCUS DEFINES AN EXPRESSION POLYMORPHISM AND A POSSIBLE RISK FACTOR TO DEVELOP RA}

${ }^{1} \mathrm{LR}$ Lard, ${ }^{1} \mathrm{JJ}$ Schonkeren, ${ }^{1} \mathrm{E}$ Pieterman, ${ }^{2} \mathrm{R}$ Westendorp, ${ }^{1} \mathrm{FC}$ Breedveld, ${ }^{1} \mathrm{TW}$ Huizinga. ${ }^{1}$ Rheumatology; ${ }^{2}$ Epidemiology, Leiden University Medical Centre, Leiden, Netherlands

\subsection{6/annrheumdis-2001.823}

Background IL-10 production differs between individuals. We have evaluated the IL-10 production in whole blood cultures with/without LPS. The comparison of monozygotic twins, sibs and unrelated individuals yielded an estimate of heritability of 70\%. The IL-10 production was associated with haplotypes defined by alleles of CA-repeats. In line with these results we have demonstrated that the interindividual differences in production of mRNA encoding IL-10 are similar than the interindividual differences in IL-10 protein production.

Objectives To define SNPs associated with common haplotypes, to study the association of IL-10 production with haplotypes/ 